\title{
Breath analysis during one-lung ventilation in cancer patients
}

\author{
Sabine Kischkel, Wolfram Miekisch, Patricia Fuchs and Jochen K. Schubert
}

\begin{abstract}
Noninvasive breath analysis may provide valuable information for cancer recognition if disease-specific volatile biomarkers could be identified. In order to compare nondiseased and diseased tissue in vivo, this study took advantage of the special circumstances of one-lung ventilation (OLV) during lung-surgery.

15 cancer patients undergoing lung resection with OLV were enrolled. From each patient, alveolar breath samples were taken separately from healthy and diseased lungs before and after tumour resection. Volatile substances were pre-concentrated by means of solid-phase microextraction, and were separated, identified and quantified by means of gas chromatography-mass spectrometry.

Different classes of volatile substances could be identified according to their concentration profiles. Due to prolonged fasting and activation of lipolysis, concentrations of endogenous acetone significantly increased during surgery. Exogenous substances, such as benzene or cyclohexanone, showed typical washout exhalation kinetics. Exhaled concentrations of potentially tumour associated substances, such as butane or pentane, were different for nondiseased and diseased lungs and decreased significantly after surgery.

Separate analysis of volatile substances exhaled from healthy and diseased lungs in the same patient, together with thorough consideration of substance origins and exhalation kinetics offers unique opportunities of biomarker recognition and evaluation.
\end{abstract}

KEYWORDS: Breath gas analysis, double-lumen endotracheal tube, one-lung ventilation, solidphase microextraction gas chromatography-mass spectrometry

I n contrast to blood analysis or tissue biopsies, analysis of exhaled breath is completely noninvasive, and sampling of breath can be performed repeatedly and frequently without any burden to the patient and without any risk for the staff collecting the samples. In recent years, potential applications of breath analysis have been suggested for detection of lung diseases and recognition of inflammatory and malignant processes in the body, as well as for detection of special diseased states such as allograft rejection and renal failure [1-5]. However, to date, none of these markers or marker sets reached clinical relevance in terms of reliable disease recognition and sufficient sensitivity and specificity. Reasons for this are the influence of inspired concentrations, prior intake and actual excretion of environmental contaminations and the huge inter- and intra-individual variations of exhaled substance concentrations [6-8]. Because of the latter, comparison of substance exhalation between different individuals has often yielded ambiguous or contradictory results.

A current treatment option for primary or secondary lung tumours consists of lung volume reduction surgery to improve lung function, health-related quality of life and physical exercise capacity. Routine surgical and anaesthetic procedures include one-lung ventilation (OLV) with a double-lumen endotracheal tube (DLT). In order to improve intra-operative conditions the diseased lung is not ventilated during surgery. Commonly used leftsided DLTs enable complete separation of left and right lungs, in such a way that lungs can be ventilated independently. In addition, mixing of exhaled gas from left and right lungs can be prevented.

This study was intended to take advantage of the special circumstances of OLV. When patients suffering from lung tumours are mechanically ventilated via DLT during lung surgery, volatile substances potentially emanating from nondiseased and diseased tissue can be compared.

The following issues were addressed in detail. 1) Which differences exist in exhaled breath composition of cancer patients before and after surgical removal of the lung tumour? If differences can be recognised, will the underlying substances be
AFFILIATIONS

Dept of Anaesthesiology and Intensive Care Medicine, University Rostock, Rostock, Germany.

CORRESPONDENCE

S. Kischkel

Dept of Anaesthesiology and Intensive Care Medicine University Rostock Schillingallee 35 18057 Rostock Germany E-mail: sabine.kischkel@unirostock.de

Received: July 222011 Accepted after revision: Dec 142011 First published online: Jan 202012 
endogenous or exogenous compounds? 2) Are there any differences in exhaled substance concentrations between healthy and diseased lungs in the same patient?

\section{MATERIAL AND METHODS Patients}

After approval by the local ethics committee (Rostock, Germany) and after having obtained written informed consent, 15 cancer patients were enrolled into the study. 12 patients had primary lung tumours, and three suffered from pulmonary metastases of renal, prostatic and uterus carcinoma, respectively. All patients had a smoking history. All patients had thoracotomy and tumour resection. OLV was instituted during surgery. For that purpose (left-sided) DLTs were introduced into patients' tracheas. During surgery, patients were brought into a lateral position in the way that the diseased side was up. Physiological parameters such as body weight, body height, blood pressure and heart rate were recorded. Demographic characteristics of patients are summarised in table 1.

\section{Breath gas sampling}

Breath samples and arterial blood samples were taken after induction of anaesthesia before lung surgery started and after the end of lung surgery. As patients had been intubated with DLTs (Robertshaw tube; Mallinckrodt Medical, Cornamaddy Athlone, Ireland), samples were drawn separately from healthy and diseased lungs.

Detailed study design and breath gas sampling are shown in figure 1. A sterilised stainless steel T-piece and the measuring cuvette of a fast-responding mainstream capnometer (Capnogard; Novametrix, Wallingford, CT, USA) had been incorporated into the respiratory circuit near the connectors of the DLTs. As described before, $15 \mathrm{~mL}$ of alveolar gas were withdrawn from the respiratory circuit under visual control of expired carbon dioxide tension $\left(\mathrm{PCO}_{2}\right)$ in such a way that gas collection took place only during the alveolar phase of expiration [6,9]. Alveolar samples from the right lung were taken from the tracheal lumen of the left-sided DLT, while both lungs were ventilated via the DLT. Samples from the left lung were taken from the endobronchial lumen of the DLT. Inspired samples were taken from medical synthetic air.

In one patient, additional alveolar breath gas samples were taken on the day before surgery under spontaneous breathing [8]. Inspired samples from this patient were taken from ambient air in parallel.

To assess contaminations coming from the DLT material, gas samples were taken from clean synthetic air that had passed through an isolated DLT. In this experimental setup a new, unused DLT was mounted into a respiratory circuit that was not connected to a patient.

All gas samples were immediately transferred into $20 \mathrm{~mL}$ evacuated sealed glass vials (Gerstel, Muelheim an der Ruhr, Germany). At least two samples for each measurement were collected and processed within $6 \mathrm{~h}$ after sampling.

\section{Analytical procedures}

Volatile substances in the samples were pre-concentrated by solid-phase microextraction (SPME) as described before in detail [8]. A CTC Combi PAL SPME autosampler was used for automatic pre-concentration and desorption of the volatile organic compounds. The gas chromatography-mass spectrometry (GC-MS) analyses were performed with a Varian Star 3900 CX gas chromatograph (Varian, Palo Alto, CA, USA) and a Varian Saturn 2100 mass ion trap spectrometer (Varian) using electron impact ionisation (EI, $70 \mathrm{eV}$ ).

A selection of 38 volatile organic substances (hydrocarbons, ketones, aldehydes, alcohols, acetonitrile, dimethylsulfide and aromatic compounds) were quantified in the (breath) samples by means of calibrations performed in the range of 0.10 $60.58 \mathrm{nmol} \cdot \mathrm{L}^{-1}$ (table 2). Details of the analytical methods have been described before [8]. Briefly, linear ranges, limits of detection (LODs) and limits of quantification (LOQs) were

TABLE 1 Patient demographics and diagnoses

\begin{tabular}{|c|c|c|c|c|c|}
\hline Patient & Age yrs & Sex & Tumour location & Tumour histology & Surgery \\
\hline 1 & 62 & Male & Right (S3) & Neuroendocrine ca. & Tumour resection \\
\hline 2 & 68 & Male & Right upper lobe & NSCLC (squamous cell ca.) & Lobectomy \\
\hline 3 & 74 & Male & Right (S3) & NSCLC (squamous cell ca.) & Atypical resection \\
\hline 4 & 70 & Male & Right (S1, S3) & NSCLC (adenous ca.) & Atypical resection \\
\hline 5 & 78 & Male & Right upper lobe & NSCLC (squamous cell ca.) & Lobectomy \\
\hline 6 & 72 & Male & Right middle lobe & NSCLC (squamous cell ca.) & Lobectomy \\
\hline 7 & 74 & Male & Right inferior lobe & NSCLC (squamous cell ca.) & Lobectomy \\
\hline 8 & 74 & Male & Left inferior lobe & NSCLC (squamous cell ca.) & Lobectomy \\
\hline 9 & 61 & Male & Right (S1, S7, S4) & Metastases of renal ca. & Atypical resection \\
\hline 10 & 73 & Male & Left lobe & NSCLC (squamous cell ca.) & Tumour resection, decortication \\
\hline 11 & 70 & Male & Right (S10) & NSCLC (squamous cell ca.) & Atypical resection \\
\hline 12 & 72 & Male & Left (S1, S2) & Metastases of prostatic ca. & Atypical resection \\
\hline 13 & 79 & Male & Right inferior lobe & NSCLC (large cell ca.) & Lobectomy \\
\hline 14 & 48 & Female & Left upper lobe & Metastases of cervix ca. & Atypical resection \\
\hline 15 & 73 & Female & Right upper lobe & NSCLC (adenous ca.) & Lobectomy \\
\hline
\end{tabular}

S: lung segment; NSCLC: nonsmall cell lung cancer; ca:: carcinoma 


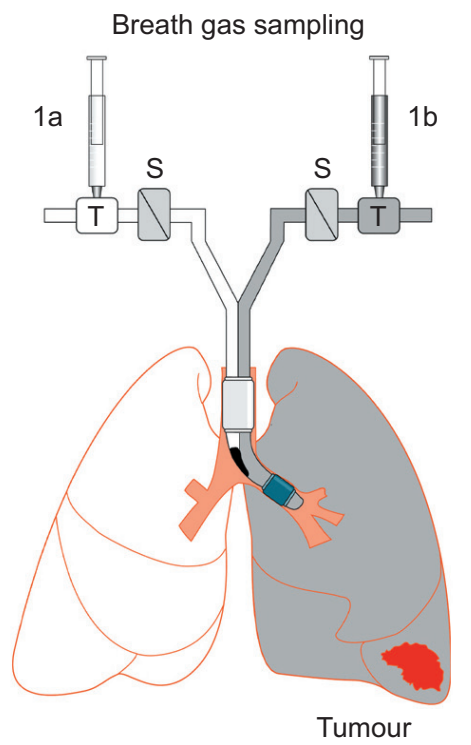

Before surgery

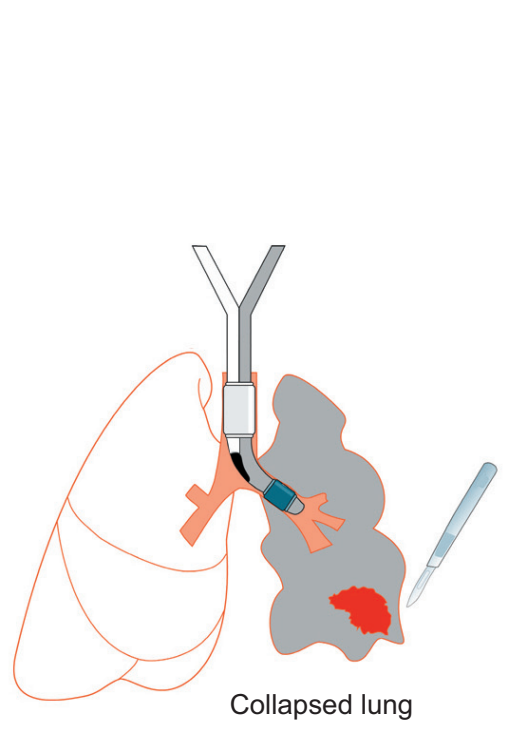

During surgery (OLV)

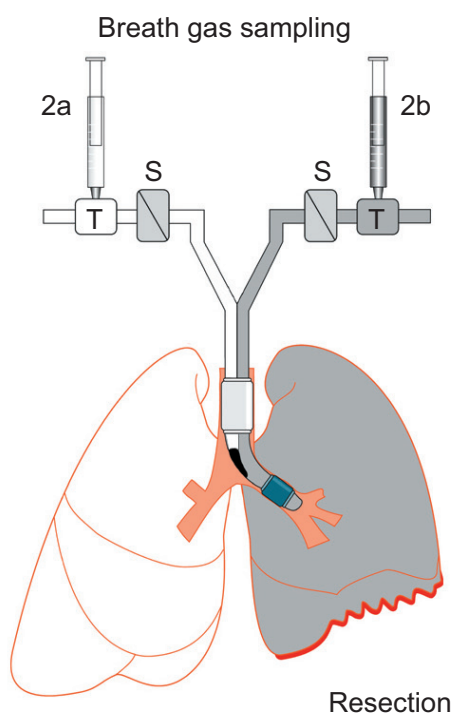

After surgery

FIGURE 1. Schematic drawing of distinct breath gas sampling from nondiseased and diseased lungs before and after surgery. OLV: one-lung ventilation; 1 a: manual breath gas sampling from nondiseased lungs before surgery; 2a: manual breath gas sampling from nondiseased lungs after surgery; $1 \mathrm{~b}$ : manual breath gas sampling from diseased lungs before surgery; $2 \mathrm{~b}$ : manual breath gas sampling from diseased lungs after surgery; $\mathrm{T}$ : stainless steel T-pieces with Luer Lock adapter and gas tight syringe $\mathrm{S}$ : $\mathrm{CO}_{2}$-measuring cuvette.

determined using a seven-point calibration with six repetitions. Substance identification was confirmed by comparing the retention times and mass spectra with those of pure standard substances.

\section{Statistical analysis}

Statistical calculations were performed using SigmaStat 3.5/ SigmaPlot 10.0 (Systat Software Inc., Richmond, CA, USA). Multiple comparisons between data from different measurements before and after lung-surgery were performed by means of paired t-test and repeated-measures ANOVA for normally distributed values or by means of repeated-measures ANOVA on ranks for nonparametric data. A post hoc Student-NewmanKeuls test was employed to detect significant differences between groups. Results are given as mean \pm SEM or as medians and 25th-75th percentiles, as appropriate. A p-value $<0.05$ was considered to be statistically significant. In order to reduce interindividual variations and to render results comparable, volatile organic compound concentrations in the breath samples were normalised to exhaled concentrations obtained in the samples, which were taken from the nondiseased lung directly after intubation before lung surgery started.

\section{RESULTS}

Table 2 shows LOD, LOQ and detection ranges for 38 selected volatile organic compounds.

Table 3 shows quantitative data of all compounds present in measurable concentrations in patients' exhaled breath. Five compounds had significantly different concentrations in healthy and diseased lungs or showed differences in exhaled concentrations when pre- or post-operative concentrations were determined.
Normalised acetone concentrations significantly increased during surgery. Normalised cyclohexanone, benzene, butane and pentane concentrations decreased significantly when pre-and post-surgery levels were compared. Exhaled concentrations of all other 33 compounds did not show any statistically significant differences between healthy and diseased lungs, either before or after thoracic surgery. A more detailed presentation of exhaled concentrations is shown in figure 2 and table 3.

Ratios of arterial $\mathrm{PCO}_{2}\left(\mathrm{~Pa}_{\mathrm{a}} \mathrm{CO}_{2}\right)$ and end-tidal carbon dioxide tension $\left(P \mathrm{et}, \mathrm{CO}_{2}\right)$ showed no differences when $\mathrm{PCO}_{2}$ exhalation from healthy and diseased lungs was compared before and after surgery $(\mathrm{p}=0.107)$. In healthy lungs, mean $\pm \mathrm{SEM} P \mathrm{a}, \mathrm{CO}_{2} / P$ et, $\mathrm{CO}_{2}$ was $1.09 \pm 0.04$ before surgery and $1.16 \pm 0.06$ after surgery. In diseased lungs, mean \pm SEM $P a, C_{2} / P e t, C_{2}$ was $1.07 \pm 0.04$ before surgery and $1.21 \pm 0.08$ after surgery.

Figure 3 shows mean exhaled acetone concentrations and mean arterial blood dextrose concentrations before and after lung surgery. Acetone concentrations were significantly higher after surgery than after induction of anaesthesia $(p=0.003)$. Blood dextrose concentrations showed a tendency to increase after surgery $(\mathrm{p}=0.073)$.

In samples from air that had been driven through an isolated DLT, mean substance concentrations were $73.10 \mathrm{nmol} \cdot \mathrm{L}^{-1}$ for isopropanol, $11.26 \mathrm{nmol} \cdot \mathrm{L}^{-1}$ for cyclohexanone, $0.19 \mathrm{nmol} \cdot \mathrm{L}^{-1}$ for heptane and $0.17 \mathrm{nmol} \cdot \mathrm{L}^{-1}$ for 2-butanone. All other compounds could not be detected in these samples. Figure 4 shows exhaled cyclohexanone and isopropanol concentrations in ambient air and substance concentrations in air samples from an isolated DLT. In addition, cyclohexanone and isopropanol concentrations from one patient under spontaneous breathing and under mechanical ventilation are shown. 
TABLE 2 Limit of detection (LOD), limit of quantification (LOQ) and detection ranges for volatile organic compounds in exhalation samples and samples from synthetic air from the central gas supply

\begin{tabular}{|c|c|c|c|c|}
\hline Substance & LOD nmol. $\mathrm{L}^{-1}$ & LOQ nmol. $\mathrm{L}^{-1}$ & $\begin{array}{l}\text { Detection range in exhalation } \\
\text { samples } \mathrm{nmol} \cdot \mathrm{L}^{-1}\end{array}$ & $\begin{array}{l}\text { Detection range in samples from } \\
\text { synthetic air } \mathrm{nmol} \cdot \mathrm{L}^{-1}\end{array}$ \\
\hline Isoprene & 0.024 & 0.098 & $1.54-44.15$ & $0.13-9.40$ \\
\hline Acetone & 0.266 & 0.985 & $2.93-197.86$ & $0.99-1.71$ \\
\hline 2-Butanone & 0.043 & 0.158 & $0.16-14.28$ & $0.15-1.55$ \\
\hline Cyclohexanone & 0.214 & 1.252 & $1.80-111.98$ & n.d. \\
\hline Dimethylsulfide & 0.075 & 0.270 & d. & n.d. \\
\hline Acetonitrile & 0.492 & 1.716 & $1.72-3.10$ & n.d. \\
\hline Ethanol & 1,305 & 5.098 & $5.34-373.71$ & $5.10-13.45$ \\
\hline Isopropanol & 0.205 & 0.717 & 2.87-212.69 & $1.42-58.80$ \\
\hline Acetaldehyde & 0.363 & 1.280 & $1.29-146.31$ & d. \\
\hline Propanal & 0.094 & 0.341 & $0.34-3.20$ & $0.34-0.60$ \\
\hline Butanal & 0.042 & 0.161 & $0.16-2.07$ & $0.55-0.97$ \\
\hline Pentanal & 0.121 & 0.436 & $0.44-4.16$ & $1.00-1.22$ \\
\hline Hexanal & 0.083 & 0.305 & $0.31-17.23$ & $0.31-0.79$ \\
\hline Heptanal & 0.029 & 0.116 & n.d. & n.d. \\
\hline Octanal & 0.099 & 0.365 & n.d. & n.d. \\
\hline 2-Propenal & 0.105 & 0.398 & $0.40-9.48$ & n.d. \\
\hline 2-Butenal & 0.235 & 0.872 & n.d. & n.d. \\
\hline Propane & 0.096 & 0.350 & $0.36-0.49$ & n.d. \\
\hline Butane & 0.034 & 0.131 & $0.13-3.27$ & n.d. \\
\hline Pentane & 0.119 & 0.431 & $0.43-2.23$ & n.d. \\
\hline Hexane & 0.029 & 0.114 & $0.12-1.14$ & $0.12-0.16$ \\
\hline Heptane & 0.035 & 0.129 & $0.13-0.42$ & $0.13-0.40$ \\
\hline Butane, 2-methyl- & 0.053 & 0.191 & d. & n.d. \\
\hline Propanal, 2-methyl- & 0.119 & 0.422 & n.d. & n.d. \\
\hline Butane, 2,2-dimethyl- & 0.152 & 0.522 & n.d. & n.d. \\
\hline Butane, 2,3-dimethyl- & 0.091 & 0.327 & n.d. & n.d. \\
\hline Pentane, 2-methyl- & 0.079 & 0.284 & d. & n.d. \\
\hline Pentane, 3-methyl- & 0.047 & 0.177 & n.d. & n.d. \\
\hline Pentane, 2,2-dimethyl- & 0.036 & 0.134 & n.d. & n.d. \\
\hline Pentane, 2,4-dimethyl- & 0.028 & 0.108 & n.d. & n.d. \\
\hline Pentane, 3,3-dimethyl- & 0.086 & 0.307 & n.d. & n.d. \\
\hline Hexane, 2-methyl- & 0.003 & 0.014 & n.d. & n.d. \\
\hline Cyclohexane & 0.179 & 0.619 & $0.62-1.13$ & n.d. \\
\hline Benzene & 0.029 & 0.112 & $0.12-0.21$ & n.d. \\
\hline Toluene & 0.055 & 0.199 & $0.20-0.75$ & n.d. \\
\hline Chlorobenzene & 0.059 & 0.228 & n.d. & n.d. \\
\hline Benzene, 1,2-dimethyl- & 0.082 & 0.310 & n.d. & n.d. \\
\hline Benzene, 1,2-dichloro- & 0.093 & 0.348 & n.d. & n.d. \\
\hline
\end{tabular}

n.d.: not detected (i.e. value was below LOD); d.: detected (i.e. value was between LOD and LOQ).

\section{DISCUSSION}

Separate gas sampling from nondiseased and diseased lungs was performed in patients undergoing lung surgery for tumour resection. Different classes of substances could be identified according to their concentration profiles. Endogenous bloodborne substances such as isoprene were exhaled independently from tumours and surgery. Endogenous blood-borne substances such as acetone exhibited concentration profiles linked to metabolism. Exogenous blood-borne substances such as benzene showed characteristic washout kinetics. Exogenous substances coming from ambient air or tubing such as cyclohexanone might have erroneously been taken for cancer biomarkers. Endogenous blood-borne substances such as butane and pentane might be related to tumour growth and tumour resection, respectively. Results of this study emphasise the importance of unequivocal identification of substance origins and biochemical pathways when new biomarkers are to be identified.

Substances analysed in this study were chosen according to actual knowledge on breath biomarkers. A special focus was set onto substances that have been described as potential cancer biomarkers, such as (branched) hydrocarbons [10] and oxygenated compounds [3]. In contrast to some recent studies, branched hydrocarbons could not be detected in traceable 


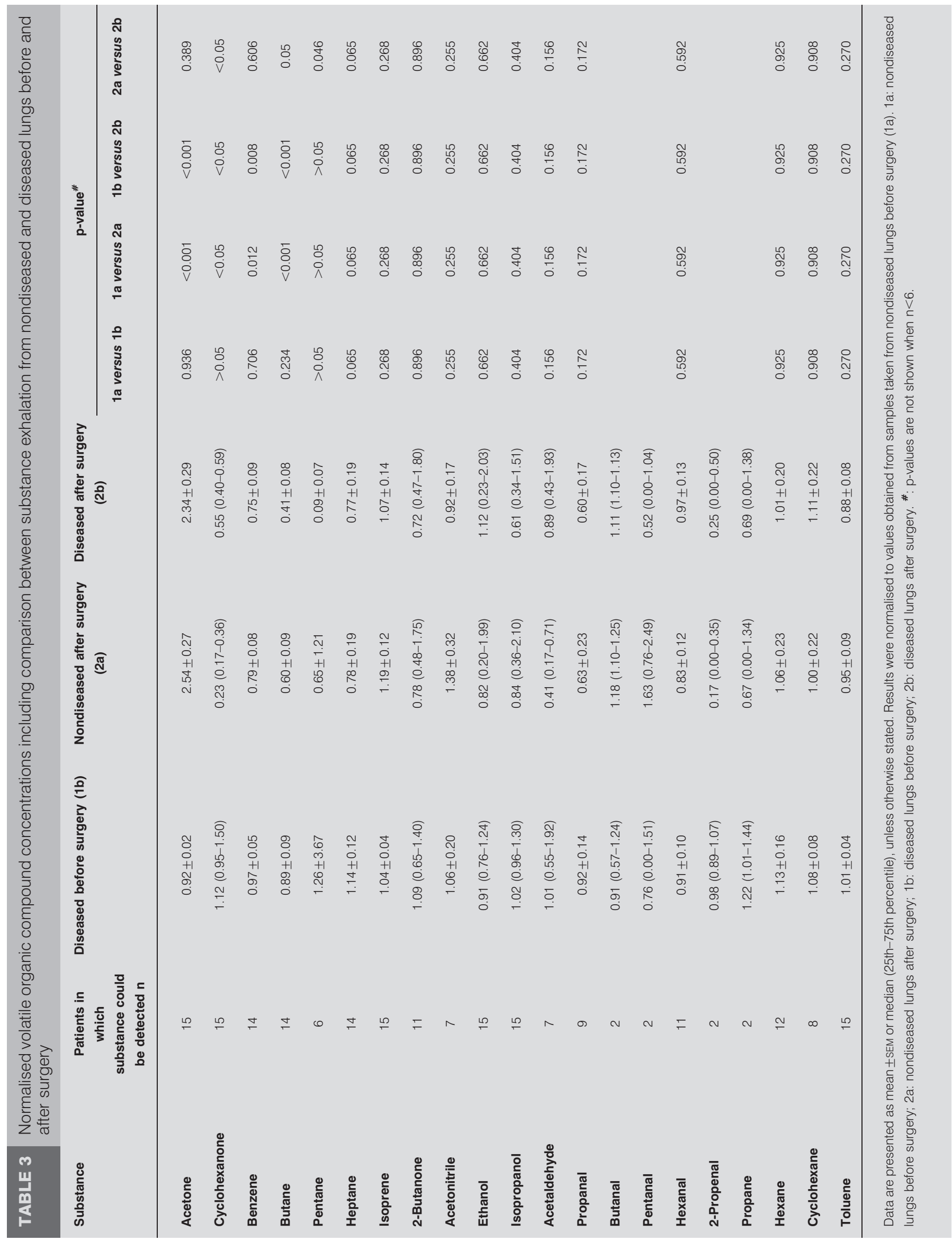




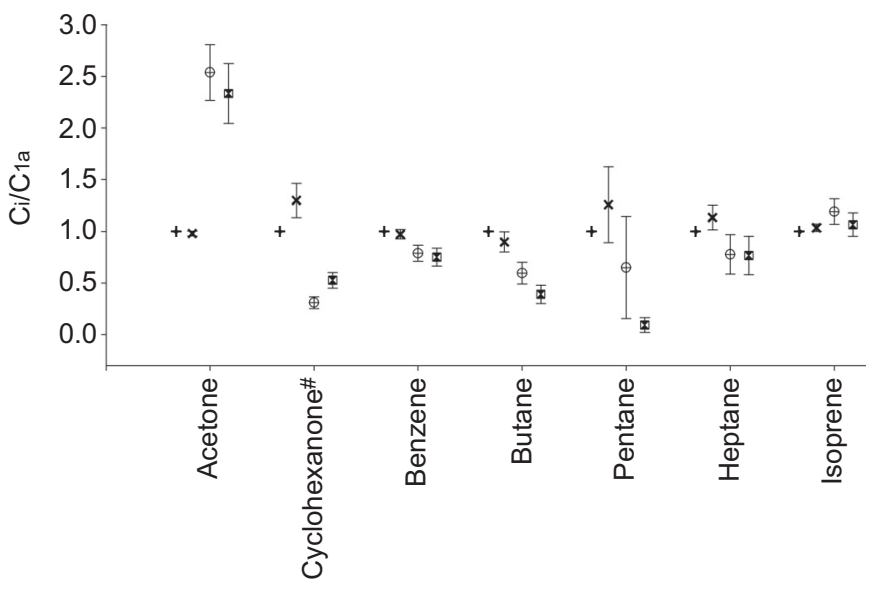

FIGURE 2. Mean values of exhaled acetone, cyclohexanone, benzene, butane, pentane, heptane and isoprene. Results were normalised to the values obtained from nondiseased lungs before surgery $(\mathrm{Ci} / \mathrm{C} 1 \mathrm{a}) .+$ : nondiseased lungs before surgery; $x$ : diseased lungs before surgery; encircled cross: nondiseased lungs after surgery; hourglass in square: diseased lungs after surgery. ${ }^{*}$ : normality test failed.

concentrations in our patients, although corresponding LODs of our method were in the range of some $\mathrm{pmol} \cdot \mathrm{L}^{-1}$ (parts per trillion-parts per quadrillion volume (pptv-ppqv)). In the cited studies, most of these substances were found in higher concentrations in inspired air than in expired air. In addition, branched hydrocarbons are known to emanate from plastic materials or paintings $[11,12]$. Hence, the origin of this type of compound must be assumed to be contamination rather than endogenous production. Acetonitrile and aromatic compounds representing smoking-related compounds [4] were found in typical concentrations in patients' exhaled air. Concentrations of these compounds did not show any differences between diseased and healthy lungs. Dimethylsulfide is known to be generated by gingival bacteria [13] and, therefore, was only detectable in very low concentrations in exhaled air from intubated and mechanically ventilated patients. Exhaled aldehyde concentrations were comparable in samples from healthy and diseased lungs. A

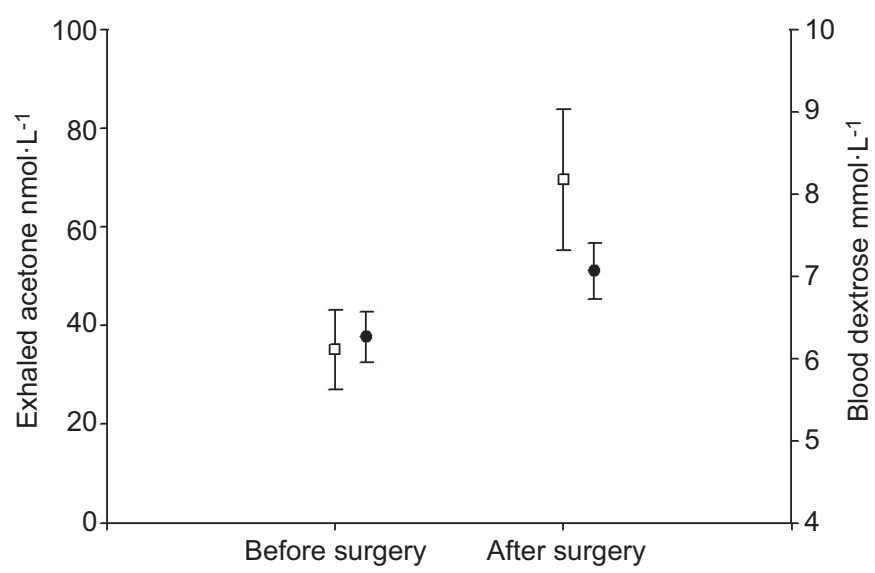

FIGURE 3. Mean values of exhaled acetone concentrations and blood dextrose concentrations before and after surgery. $\square$ : exhaled acetone concentrations; : blood dextrose concentrations.
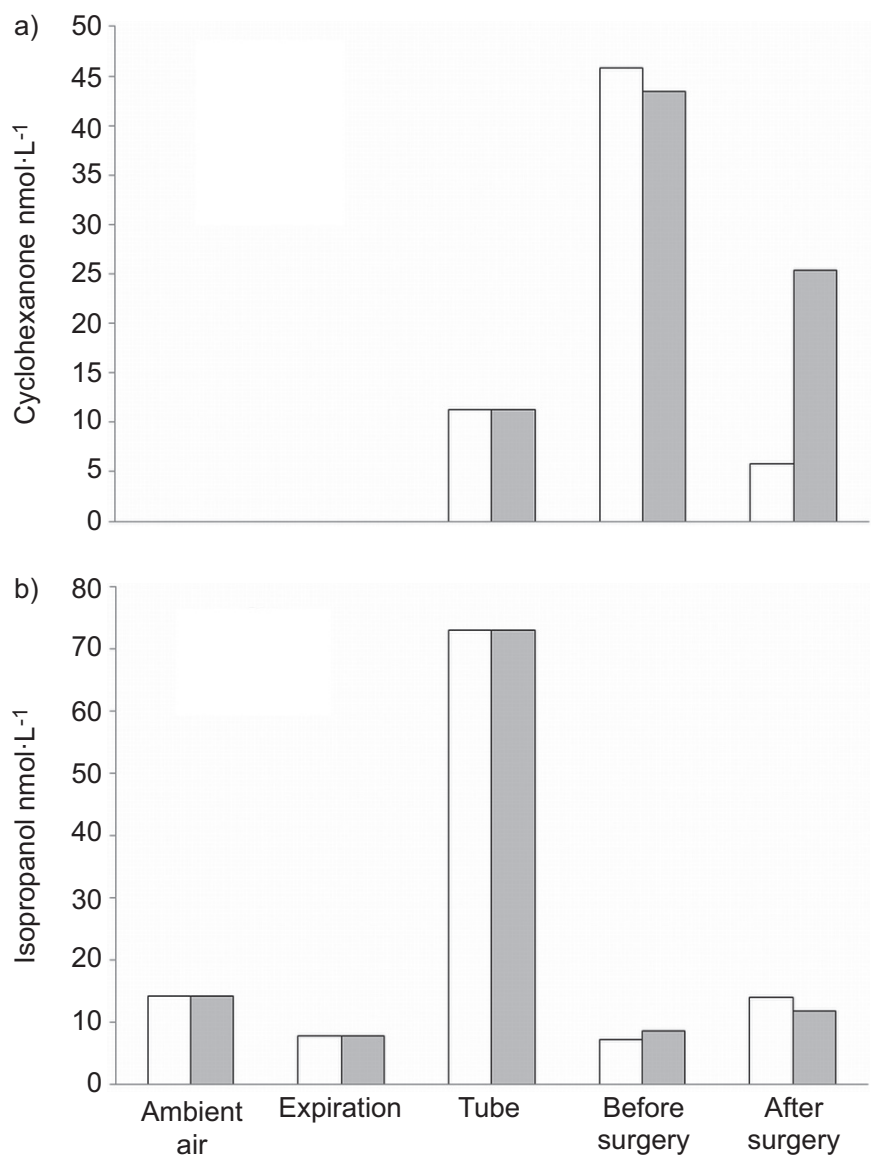

FIGURE 4. Results from one patient, who had been examined under spontaneous breathing on the day before surgery and under mechanical ventilation during lung resection on the following day. a) Cyclohexanone and b) isopropanol concentrations in ambient air, in expired air under spontaneous breathing, in medical synthetic air that had passed through an isolated double-lumen endotracheal tube, and in expired air before and after surgery under mechanical ventilation. $\square$ : nondiseased lung; 1 : diseased lung.

possible reason for that may be seen in the relatively high inspired concentrations of these compounds.

Finally, five substances showed significant differences between diseased and healthy lungs or were different when pre- and post-surgery levels were compared. These substances were acetone, butane, pentane, cyclohexanone and benzene.

As acetone is formed through decarboxylation of acetoacetate, its concentrations in blood depend on dextrose metabolism and on the extent of lipolysis [14]. Stress-induced increases in blood dextrose are known from clinical studies on outcome and serum dextrose control [15]. Lung surgery lasted between 1.5 and $5.0 \mathrm{~h}$. Therefore, exhaled acetone concentrations were additionally increased through lipolysis and ketogenesis after prolonged fasting. This phenomenon has already been observed by PABST et al. [16] and MiETH et al. [17] in patients undergoing cardiac surgery. Hence, acetone represents an interesting metabolic marker but is not a cancer specific substance. As acetone generation is not uniquely linked to dextrose metabolism, but also depends on the extent of lipolysis, exhaled acetone exhibited a more steep increase than blood dextrose. 
According to their concentration profiles, butane, pentane, cyclohexanone, benzene and heptane might have been linked to tumour growth and tumour resection, respectively.

Butane and pentane have been related to oxidative stress and bronchial carcinoma, respectively [10]. Oxidative stress is known as a fundamental mechanism associated with cancer growth. In relation to tumour growth and resection, the time profile of butane and pentane concentrations may be explained as follows. 1) Butane and pentane are linked to tumour growth as their concentrations were maximal in the diseased lungs before resection. 2) Butane and pentane generated from the tumour could be given off directly into the alveoli, but could also be secreted into the blood stream. For that reason, exhaled concentrations from the nondiseased lungs need not necessarily be zero. 3) After resection, exhaled butane and pentane concentrations dropped most in the formerly diseased lung from which the tumour had been removed. From these findings one might deduce that butane and pentane represents a marker for tumour growth in the lung. A similar tendency might be seen in the concentration profiles of heptane. As an nalkane, this substance has also already been linked to bronchial cancer [10]. As nonpolar substances, such as butane, pentane or heptane, can be stored in lipid tissues for quite a long time, it is difficult to say what amount of time would have been necessary for the exhaled concentrations to fall to "zero". Hence, the slow drop of exhaled butane, pentane and heptane concentrations would not a priori exclude these substances from being linked to tumour growth. Confirmation in a larger number of patients and meticulous tracing of biochemical pathways will be necessary before these substances can be proclaimed as biomarkers of cancerous disease.

Misthos et al. [18] reported that oxidative stress may be generated by OLV itself. In their study, severe oxidative burden occurred a few minutes after re-expansion of the atelectatic lung. In contrast to these results, concentrations of all oxidative stress markers decreased after surgery and lung re-expansion in our study. This might be due to the fact that breath gas sampling was not performed immediately after re-expansion of the lung.

Despite its seemingly tumour-specific concentration profile, cyclohexanone is not a cancer biomarker but simply originates from the material of the Robertshaw tubes. As cyclohexanone emanated from the tubes, concentrations changes typically mirrored washout kinetics of a substance that comes from inspired air. Since the diseased lung was not ventilated during surgery, washout at the end of surgery was not complete when compared with the nondiseased lung, which had constantly been ventilated. Cyclohexanone is an organic solvent used in the production of medical devices made of polyvinyl chloride, such as intravenous fluid bags, endotracheal tubes, extracorporeal circulation tubing, extracorporeal membrane oxygenation devices and haemodialysis membranes. The toxicity of polyvinyl chloride and cyclohexanone has been assessed in animal models. The substance may cause decreased cardiac and cell viability $[19,20]$, depressed cardiac contractility [19, 21], neurological abnormalities [22], oedema [19] and death or moribund state $[19,22]$. Without consideration of substance origins and without taking into account potential contaminations from ambient air or tubing materials, cyclohexanone would certainly have been mistaken as a potential biomarker.
Benzene represents a compound typically occurring in cigarette smoke and being stored in different body compartments [4, 23-25]. In this study, all patients were ex-smokers. During lung surgery, substance concentrations followed classical washout kinetics.

Isopropanol represents a typical ingredient of disinfectants. Hence, it is not surprising that isopropanol concentrations were extremely high in samples from the air that had passed through an isolated DLT.

Isoprene could be detected in all investigated samples. As isoprene is linked to cholesterol biosynthesis [26], its exhalations did not depend on surgery or presence of tumour in any way.

Exhaled substance concentrations showed considerable interindividual variations. For that reason concentrations were normalised in the way that each patient served as his own control and effects of inter-individual variation were reduced.

As for every other method applied in breath analysis, there are limitations of the SPME GC-MS analysis, e.g. in terms of LOD/ LOQ. However, for most of the compounds under investigation, LOD/LOQs were in the low $\mathrm{nmol} \cdot \mathrm{L}^{-1}(\mathrm{pptV})$ range and, therefore, are comparable with or even better than those of other methods published in the field. In addition, virtually all compounds will be detectable from the environment when concentration ranges below pptV are considered.

OLV is widely used in thoracic surgery. During lung surgery the patients are laterally positioned onto the side of the healthy lung and the operated lung remains completely atelectatic for a period of time. As a consequence, the nonventilated lung is also hypoperfused due to hypoxic pulmonary vasoconstriction [27]. It is difficult to foresee which kind of ventilation/perfusion mismatch might be predominant after re-expansion of the operated lung. Shunt perfusion due to persistent atelectasis might occur as dead space ventilation due to patients' lateral position. For that reason, dead space correction by means of arterial and end-tidal carbon dioxide measurement will produce erroneous results when shunt perfusion prevails. In addition, exhalation of substances with low water solubility, such as butane, pentane and heptane, does not depend on dead space ventilation in the same way as carbon dioxide. For these reasons, we did not apply dead space correction by means of the ratio of end-tidal and arterial $\mathrm{PCO}_{2}$. In addition, the extent of dead space ventilation in terms of mean $\mathrm{Pa}, \mathrm{CO}_{2} / \mathrm{Pet}_{\mathrm{et}} \mathrm{CO}_{2}$ was not different before and after lung surgery.

In conclusion, OLV for resection of bronchial carcinoma proved to be a valuable setting for assessing potentially tumour-specific volatile substances. Separate analysis of volatile substances exhaled from healthy and diseased lungs in the same patient, together with thorough consideration of substance origins and exhalation kinetics, offers unique opportunities of biomarker recognition and evaluation.

\section{SUPPORT STATEMENT}

This research was supported by the European Commission through the STREP project BAMOD (Sixth Frame Program, project no LSHC-CT2005-019031).

\section{STATEMENT OF INTEREST}

None declared. 


\section{REFERENCES}

1 Buszewski B, Kesy M, Ligor T, et al. Human exhaled air analytics: biomarkers of diseases. Biomed Chromatogr 2007; 21: 553-566.

2 Chan HP, Lewis C, Thomas PS. Exhaled breath analysis: novel approach for early detection of lung cancer. Lung Cancer 2009; 63: 164-168.

3 Fuchs P, Loeseken C, Schubert JK, et al. Breath gas aldehydes as biomarkers of lung cancer. Int J Cancer 2009; 126: 1663-1670.

4 Gordon SM, Wallace LA, Brinkman MC, et al. Volatile organic compounds as breath biomarkers for active and passive smoking. Environ Health Perspect 2002; 110: 689-698.

5 Horváth I, Lázár Z, Gyulai N, et al. Exhaled biomarkers in lung cancer. Eur Respir J 2009; 34: 261-275.

6 Schubert JK, Miekisch W, Birken T, et al. Impact of inspired substance concentrations on the results of breath analysis in mechanically ventilated patients. Biomarkers 2005; 10: 138-152.

7 Pleil JD. Influence of systems biology response and environmental exposure level on between-subject variability in breath and blood biomarkers. Biomarkers 2009; 14: 560-571.

8 Kischkel S, Miekisch W, Sawacki A, et al. Breath biomarkers for lung cancer detection and assessment of smoking related effects confounding variables, influence of normalization and statistical algorithms. Clin Chim Acta 2010; 411: 1637-1644.

9 Birken T, Schubert J, Miekisch W, et al. A novel visually $\mathrm{CO}_{2}$ controlled alveolar breath sampling technique. Technol Health Care 2006; 14: 499-506.

10 Phillips M, Cataneo RN, Cummin AR, et al. Detection of lung cancer with volatile markers in the breath. Chest 2003; 123: 2115-2123.

11 Cox SS, Little JC, Hodgson AT. Measuring concentrations of volatile organic compounds in vinyl flooring. J Air Waste Manag Assoc 2001; 51: 1195-1201.

12 Fortmann R, Roache N, Chang JC, et al. Characterization of emissions of volatile organic compounds from interior alkyd paint. J Air Waste Manag Assoc 1998; 48: 931-940.

13 Van den Velde S, van Steenberghe D, Van Hee P, et al. Detection of odorous compounds in breath. J Dent Res 2009; 88: 285-289.

14 Deng C, Li N, Wang X, et al. Rapid determination of acetone in human blood by derivatization with pentafluorobenzyl hydroxylamine followed by headspace liquid-phase microextraction and gas chromatography/mass spectrometry. Rapid Commun Mass Spectrom 2005; 19: 647-653.
15 van den Berghe G, Wouters P, Weekers F, et al. Intensive insulin therapy in the critically ill patients. N Engl J Med 2001; 345: 1359-1367.

16 Pabst F, Miekisch W, Fuchs P, et al. Monitoring of oxidative and metabolic stress during cardiac surgery by means of breath biomarkers: an observational study. J Cardiothorac Surg 2007; 2: 37.

17 Mieth M, Schubert JK, Groger T, et al. Automated needle trap heart-cut GC/MS and needle trap comprehensive two-dimensional GC/TOF-MS for breath gas analysis in the clinical environment. Anal Chem 2010; 82: 2541-2551.

18 Misthos P, Katsaragakis S, Milingos N, et al. Postresectional pulmonary oxidative stress in lung cancer patients. The role of one-lung ventilation. Eur J Cardiothorac Surg 2005; 27: 379-382.

19 Gupta PK, Lawrence WH, Turner JE, et al. Toxicological aspects of cyclohexanone. Toxicol Appl Pharmacol 1979; 49: 525-533.

20 Cruickshank CN, Hooper C, Lewis HB, et al. The toxicity of rubbers and plastics used in transfusion-giving sets. J Clin Pathol 1960; 13: 42-50.

21 Meijler FL, Willebrands AF Jr, Durrer D. [Influence of plastic material (polyvinyl chloride) on the isolated and surviving heart of the rat]. Dia Med 1960; 32: 2882-2886.

22 Koeferl MT, Miller TR, Fisher JD, et al. Influence of concentration and rate of intravenous administration on the toxicity of cyclohexanone in beagle dogs. Toxicol Appl Pharmacol 1981; 59: 215-229.

23 Alonso M, Castellanos M, Martin J, et al. Capillary thermal desorption unit for near real-time analysis of VOCs at sub-trace levels. Application to the analysis of environmental air contamination and breath samples. J Chromatogr B 2009; 877: 1472-1478.

24 Van Berkel JJ, Dallinga JW, Moller GM, et al. Development of accurate classification method based on the analysis of volatile organic compounds from human exhaled air. J Chromatogr B 2008; 861: 101-107.

25 Perbellini L, Princivalle A, Cerpelloni M, et al. Comparison of breath, blood and urine concentrations in the biomonitoring of environmental exposure to 1,3-butadiene, 2,5-dimethylfuran, and benzene. Int Arch Occup Environ Health 2003; 76: 461-466.

26 Deneris ES, Stein RA, Mead JF. In vitro biosynthesis of isoprene from mevalonate utilizing a rat liver cytosolic fraction. Biochem Biophys Res Commun 1984; 123: 691-696.

27 Sylvester JT. Hypoxic pulmonary vasoconstriction: a radical view. Circ Res 2001; 88: 1228-1230. 